\title{
The Keep-Right-Except-To-Pass Rule
}

\author{
Jing-yan Liu \\ North China Electric Power University in Baoding, HeBei province, China
}

\begin{abstract}
In this paper, We develop a model to show how The Keep-Right-Except-To-Pass Rule will do. According to the classic three parameters relationship of the traffic flow, speed and density. After that, we weighed the proportion among the three parameters in different situations to better prove the correctness of our model. Then, our team doubts and analyze that if the left-hand rule taking place of the right-hand rule is still reasonable in our model, if not, we should adjust the model. Last, we consider how the traffic will perform under the complete intelligent transportation system, and analyze that to what extent the system will influence the traffic flow.
\end{abstract}

Index Terms - Relationship of the traffic flow; Speed; Density

\section{Introduction}

In this paper, We develop a model to show how The Keep-Right-Except-To-Pass Rule will do. According to the classic three parameters relationship of the traffic flow, speed and density. After that, we weighed the proportion among the three parameters in different situations to better prove the correctness of our model. Then, our team doubts and analyze that if the left-hand rule taking place of the right-hand rule is still reasonable in our model, if not, we should adjust the model. Last, we consider how the traffic will perform under the complete intelligent transportation system, and analyze that to what extent the system will influence the traffic flow.

\section{Velocity and Traffic Flow}

We think that there must exist close relationship between speed and the traffic. Through this thought, we find the famous three-parameter relationship between traffic flow. If we assume that $\mathrm{U}$ represents velocity, $\mathrm{V}$ represents traffic flow and $\mathrm{K}$ represents the density, there exists such mathematics relation. $\mathrm{V}=\mathrm{UK}$. Besides, $\mathrm{Kj}$ represents blocking density and Uo represents average speed when $\mathrm{U}=0$. We usually assume that the density $\mathrm{K}$ and traffic flow $\mathrm{V}$ are in linear relationship(Greenshields assumption) so that we can deduced quadratic parabolic relationship model velocity $\mathrm{U}$ and traffic flow $\mathrm{V}$, that is

$\mathrm{V}=\mathrm{Kj}\left(\mathrm{U}-\mathrm{U}^{2} / \mathrm{Uo}_{0}\right)$

From a dissertation, when traffic reaches its capacity, road has a traffic jam, at this time, even though the number of vehicles arriving is increasing, the number of the vehicle passed can not be greater than the capacity of road traffic, the number of remaining vehicles will be waiting in line.[5] According to standardized speed model, these vehicles pass at the speed of $U m(U m=0.5 \mathrm{Uo})$, so do the waiting vehicles. But in that case, it don't deduce the waiting time until the waiting vehicles have evacuated(the figure 1 has shown this case). So the average passing speed of vehicles arrived in the period should be lower than Um, that is to say, traffic flow - velocity model should be S-curve.

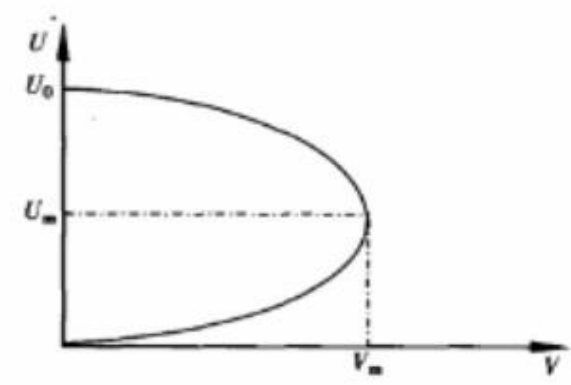

Fig.1 The relationship between speed of the vehicle and the traffic flow

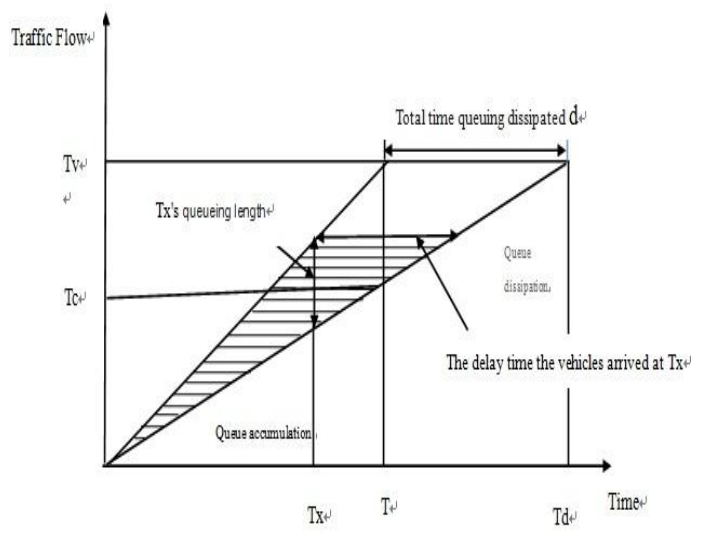

Fig.2 The relationship between the traffic flow and the time

According to this picture, we can know $\mathrm{N}=\mathrm{TV}$. Next we assume $\mathrm{D}$ represents the vehicles delayed in the period, so we get $\mathrm{D}=1 / 2$.T.V.D .

From the picture, according to the similar triangles.

$\mathrm{Td} / \mathrm{d}=\mathrm{T} . \mathrm{V} /(\mathrm{T} . \mathrm{V}-\mathrm{T} . \mathrm{C})$

$(\mathrm{T}+\mathrm{d}) / \mathrm{d}=\mathrm{V} /(\mathrm{V}-\mathrm{C})$

$\mathrm{d}=\mathrm{T} .(\mathrm{V} / \mathrm{C}-1)$

$\mathrm{d}($ average $)=\mathrm{D} / \mathrm{N}=\frac{1}{2} \cdot \mathrm{T} \cdot \mathrm{V} \cdot \mathrm{d} /(\mathrm{T} \cdot \mathrm{V})=1 / 2 \cdot \mathrm{T} /(\mathrm{V} / \mathrm{C}-1)$

$\mathrm{T}+\mathrm{d}$ (average) is

$\mathrm{L}=\mathrm{T} . \mathrm{Um}$

Here, $d$ (average) represents the average delay time in the $\mathrm{T}$ period. $\mathrm{L}$ denote the actual driving distance. Next, the average driving speed of the vehicles arrived during the $\mathrm{T}$ is 
$\mathrm{U}=\mathrm{L}(\mathrm{T}+\mathrm{d}($ average $))=\frac{2 \mathrm{Um}}{1+\mathrm{V} / \mathrm{C}}=\frac{\mathrm{Uo}}{1+\mathrm{V} / \mathrm{C}}$

What is deduced above is based on theory, however, in fact, traffic is instability when the traffic flow has reached the capacity of the road. At this time , any little impact on traffic will cause even more delay. Therefore, we have to modify the (7). Modified result is

$\mathrm{U}=\frac{\mathrm{Uo}}{1+\alpha(\mathrm{V} / \mathrm{C})^{\beta}}$

(8) is the same with U.S. Federal Highway Administration Traffic impedance model. In order to decrease the error, we continue to modify the formula. We get

$\mathrm{U}=\frac{\alpha \mathrm{Us}}{1+\gamma(\mathrm{V} / \mathrm{C})^{\beta}}$

According to the literature[5], we get the following formula.

$\mathrm{U}=\frac{\alpha 1 . \mathrm{Us}}{1+(\mathrm{V} / \mathrm{C})^{\beta}}$

$\beta=\alpha 2+\alpha 3 \cdot(\mathrm{V} / \mathrm{C})^{3}$

TABLE 1 The highway speed - flow model parameters table.

\begin{tabular}{|c|c|c|c|c|c|}
\hline Highway Type & $\mathrm{Us}(\mathrm{km} / \mathrm{h})$ & $\mathrm{C}(\mathrm{pcu} / \mathrm{h} /$ lane $)$ & $\alpha 1$ & $\alpha 2$ & $\alpha 3$ \\
\hline Highway & 120 & 2200 & 0.93 & 1.88 & 4.85 \\
\hline
\end{tabular}

In China, general standards for the highway speed limit is $100 \mathrm{~km} / \mathrm{h}$ to $120 \mathrm{~km} / \mathrm{h}[6]$. We treat this regulation as the original regulation.

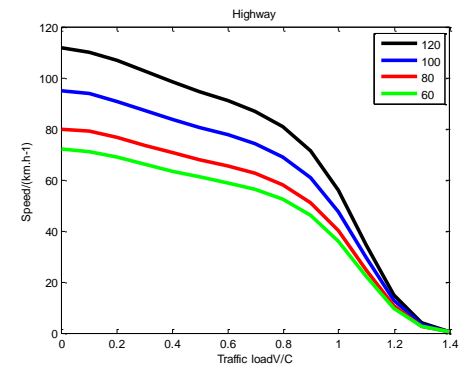

Fig.3: Mainly consider the congestion in the highway

In the figure 3, we analyze the relationship of the two parameters. As we can see, traffic load was negatively correlated with the speed at the design being $120 \mathrm{~km} / \mathrm{h}$. Meanwhile, the vehicle speed will be close to $0 \mathrm{~km} / \mathrm{h}$ when the traffic load is tend to be $1.4(\mathrm{~V} / \mathrm{C}=1.4)$.

\section{Safety and Velocity}

Firstly, we can think about that the safety has close relation with the transportation rules and the driving speed. By means of seeking many researches, we get a graph indicated the relation between accident rate and traffic load.

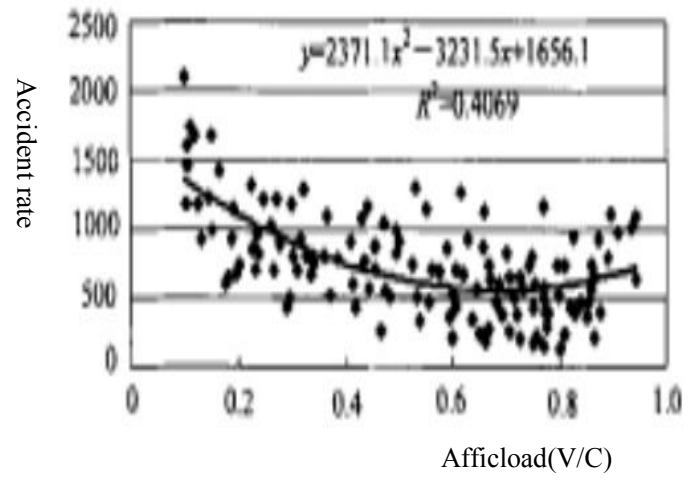

Fig.4 The relationship between the Accident rate and the afficload

This data is measured on 23 basic road during 6 years so that the relation curve between accident and traffic load(V/C) is universal significance. In the picture, y denotes the accident rate of one vehicle one million $\mathrm{km} / \mathrm{h}$, $\mathrm{x}$ denotes the value of traffic load(V/C). According to Traffic Engineering Principles, the driving speed and the traffic density are in negative correlation, V/C will increase with the increase of traffic flow, and the utilization of the road will be more. Some interference occurs between vehicles, the driving speed is getting lower, driver's alertness has enhanced, so the accident rate is getting lower. The accident rate will be lowest when $\mathrm{V} / \mathrm{C}$ reaches a relatively high value. However, if $\mathrm{V} / \mathrm{C}$ is on second increase, the demand of overtaking is increasing because of the large density and low speed [7].

\section{The Comparison of the Left-Hand Rule and Right- Hand Rule}

There exists two access system. One is left-hand rule, the other is the right-hand rule. Almost $90 \%$ countries implement the right line system, and others choose the left line system.

1) The right eye is dominated in the human vision, so the driver's seat is positioned on the right side of the vehicle, and the driver can easily observe the opposite situation.

2) Drivers can use the left hand to maintain control of the steering wheel, while using the right hand to complete the shift operation instrument, and some complex movements, which is enabling to right-handed drivers.

3) Most countries have adopted such rules, drivers accustomed to driving on the right in these countries do not have to spend time to become familiar with the new traffic rules.

However, the greatest advantage of driving on the left is the instinct to avoid damage. In the case of rapid human movement, when found danger ahead, people instinctively turned to lean to the left or to protect the position of the heart.

But given that the seat of the driver is on the right side of the vehicle

\section{Intelligent Transportation System Control}

Intelligent Transportation Systems (Intelligent Transport System or Intelligent Transportation System, referred to as ITS) is an advanced information technology, communications 
technology, sensor technology, control technology and computer technology, applied to effectively integrate the entire transportation management system, and established within a wide range, full play to the role of real-time, accurate and efficient integrated transport and management system.[10].

To some extent, the intelligent transportation system has some impact on the traffic and road safety.

1) One of the advantage of intelligent transportation system is the fact that the system can promote the traffic flow. But because of this situation, the value of $\mathrm{V} / \mathrm{C}$ will be higher than1, and According to the conclusion, we know that the accident rate will increase if the $\mathrm{V} / \mathrm{C}$ is higher than 1. Therefore, our model is influenced by the fact.

2) The intelligent transportation system is made by some machine, which may produce a variety of uncertain factors. If the system has collapsed, the accident may happen so that increase the accident rate during this time.

3) Sometimes we cannot handle the problem in case of emergency so that the information we get from the system may be wrong, causing that the driver cannot drive at an appropriate speed, then the accident is most likely happen at this time.

As for the limitation of the intelligent transportation system will have some influence on the traffic, we should make some changes in the present the-keep-right rule.

According to observations Glennon and Harwood[12], the following is the relationship between the speed of the overtaking vehicle accelerated $\mathrm{Vp}$, the speed of the vehicle overtaken Vover and road design speed v.

From some research, we get the following formula, here, $\mathrm{V}(\mathrm{A})$ min denotes the lowest speed of $\mathrm{A}$, and the $\mathrm{V}(\mathrm{A})$ max denotes the highest speed of $\mathrm{A}$, the meaning of $\mathrm{Sw}, \mathrm{S} 1, \mathrm{~S} 2, \mathrm{~S} 3, \mathrm{~S} 4$ are showed on the picture 2. denotes the speed of the overtaking vehicle a, and the denotes the speed of the vehicle c driving from the opposite side. T represents the total overtaking time. represents the response lag time in the process of overtaking. $\mathrm{hA}, \mathrm{hB}$ are the safety distance of vehicle $A$ and vehicle $B$ [13][14].

$$
\begin{aligned}
& \frac{\mathrm{V}(\mathrm{A}) \max +\mathrm{V}(\mathrm{A}) \min }{2} *\left(\mathrm{~T}-2 * \mathrm{t}_{0}\right)=\mathrm{V}(\mathrm{B}) * \mathrm{~T}+\mathrm{h}_{\mathrm{A}}+\mathrm{h}_{\mathrm{B}} \\
& \mathrm{S}_{\mathrm{w}}=\mathrm{S}_{1}+\mathrm{S}_{2}+\mathrm{S}_{3}+\mathrm{S}_{8}+\mathrm{S}_{7}=\mathrm{S}_{\mathrm{A}}+\mathrm{S}_{8}+\mathrm{S}_{7} \\
& \mathrm{~S}_{8}=\left(\mathrm{V}_{\mathrm{a}}-\mathrm{V}_{\mathrm{c}}\right) * \mathrm{t}_{1}+2 *\left(\mathrm{~V}_{\mathrm{a}}-\mathrm{V}_{\mathrm{c}}\right)^{2} /\left(2 * \mathrm{a}_{\mathrm{A}}\right)-\mathrm{V}_{\mathrm{a}}{ }^{2}+\mathrm{V}_{\mathrm{a}} * \frac{\mathrm{t}_{2}}{2}+\Delta \mathrm{s} \\
& \mathrm{S}_{7}=\mathrm{V}_{\mathrm{c}} * \mathrm{~T} \\
& \mathrm{~S}_{\mathrm{A}}=(\mathrm{V}(\mathrm{A}) \max +\mathrm{V}(\mathrm{A}) \min ) *\left(\mathrm{~T}-2 * \mathrm{t}_{0}\right) \\
& \mathrm{t}_{0}=3 \mathrm{~s}
\end{aligned}
$$

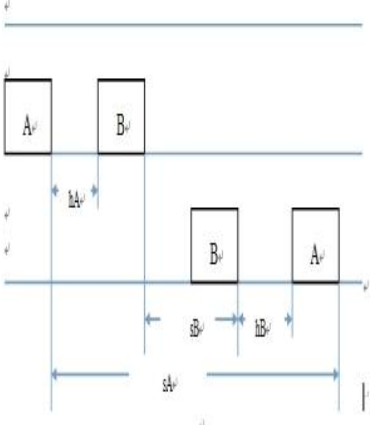

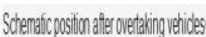

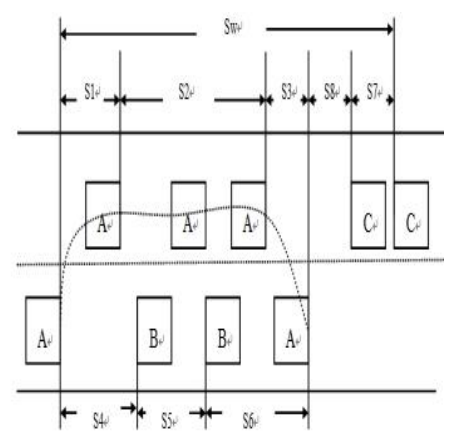

Schemaic constant overtaking safely distance-
Fig 5 Schematic diagram

After we get the integration data, we assume that the vehicle $B$ and the vehicle $C$ drive at a constant speed, and the initial velocity of vehicle $A\left(t_{0}\right)$ is higher than the speed of vehicle $\mathrm{B}$. According to these data, we can get the $\mathrm{Sw}$, i.e. the safe distance of overtaking, then we compare the real data get from the intelligent system with the theory value calculated from our model, if the real distance is higher than the $\mathrm{Sw}$ (the theory value), we can overtake safely.

\section{References}

[1] China Agricultural University Institute. Beijing 100083; Beijing Simulation Center. Beijing 100854.

[2] Yukai, Xuechanghong, Tanjuan. Real-time traffic analysis and optimal control. Dept. of Mathematics, SWJTU, Chengdu 610031, China.

[3] Addison, Low Paul S, David J. Order and chaos in the dynamics of vehicle platoons. Traffic Engineering \& Control, 1996, 37(7-8): 456459.

[4] Daganzo C F, Cassidy M J, Bertini R L. Possible explanation of phase transitions in highway traffic. Transportation Research, Part A, 1999, 33(5): 365-379.

[5] Wang wei. College of Transportation University. Nanjing 210096, China.

[6] Road Traffic Safety Law.

[7] Jixaiojin, Fangshouen, Huangjin. Transportation Engineering. Tongji university. Shanghai. 200092.

[8] Duboying. Transportation Engineering. Tongji university. Shanghai. 200092.

[9] Wuyihu, Huzhiping. Transportation Engineering. Changsha University. Hunan, Changsha. 41006.

[10] Baidu encyclopedia. http://baike.baidu.com/view/1488750.htm.

[11] http://baike.baidu.com/view/2103063.htm.

[12] GLENNON J C. New and important model of passing sight distance on two-lane highways//Transportation Research Record. 1988, 1195:132137.

[13] XuYing, YUE Da-jun, Zhaoyang, Zhangguangzhi. Teching \& Research Section of Vehicle Engineering, College of Engineering,Human Agriculture University. Changsha 410128, China.

[14] Tang Tie-qiao, HUANG Hai-jun, MEI Chao-qun. school of Economics and Management, Beijing University of Aeronautics and Astronautics, Beijing 100083; China. Basic Department, Capital University of Economics and Business, Beijing, 100070, China. 